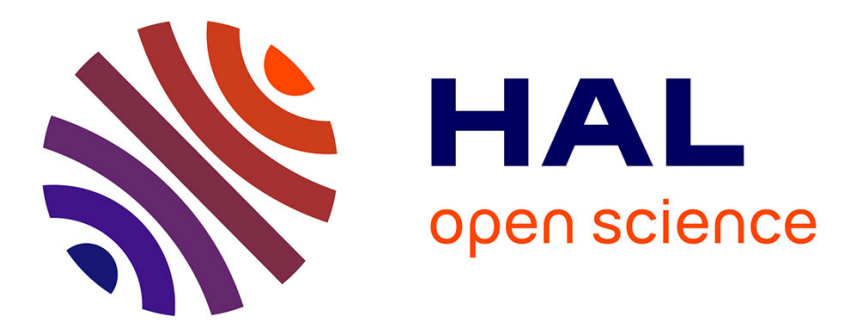

\title{
Structure and hardness of titanium surfaces carburized by pulsed laser melting with graphite addition
}

\author{
Bruno Courant, Jean-Jacques Hantzpergue, Ludovic Avril, Stéphane
}

Benayoun

\section{- To cite this version:}

Bruno Courant, Jean-Jacques Hantzpergue, Ludovic Avril, Stéphane Benayoun. Structure and hardness of titanium surfaces carburized by pulsed laser melting with graphite addition. Journal of Materials Processing Technology, 2005, 160 (3), pp.374-381. 10.1016/j.jmatprotec.2004.06.025 . hal01007335

\section{HAL Id: hal-01007335 \\ https://hal.science/hal-01007335}

Submitted on 20 Nov 2017

HAL is a multi-disciplinary open access archive for the deposit and dissemination of scientific research documents, whether they are published or not. The documents may come from teaching and research institutions in France or abroad, or from public or private research centers.
L'archive ouverte pluridisciplinaire HAL, est destinée au dépôt et à la diffusion de documents scientifiques de niveau recherche, publiés ou non, émanant des établissements d'enseignement et de recherche français ou étrangers, des laboratoires publics ou privés. 


\title{
Structure and hardness of titanium surfaces carburized by pulsed laser melting with graphite addition
}

\author{
Bruno Courant $^{\mathrm{a}, *}$, Jean Jacques Hantzpergue ${ }^{\mathrm{b}}$, Ludovic Avril ${ }^{\mathrm{b}}$, Stéphane Benayoun ${ }^{\mathrm{b}}$ \\ a Laboratoire d'Application des Matériaux à l aMécanique, CRTT, Boulevard de l'Université, BP 406, 44602 Saint-Nazaire Cedex, France \\ ${ }^{\mathrm{b}}$ Laboratoire Proc'ed'es Mat'eriaux Instrumentation, ENSAM, 2 Boulevard du Ronceray, BP 3525, 49035 Angers Cedex, France
}

\begin{abstract}
Titanium foils coated with graphite films $20 \mu \mathrm{m}$ thick were irradiated by means of a pulsed Nd-YAG in order to harden this metal by surface melting and alloying. The relationships between irradiation parameters, microstructure and hardness of the synthesized composite coatings were determined. Four relevant parameters were defined as governing the irradiation processes. The parametric working field of the laser source was investigated next to its periphery. The influences of the relevant irradiation parameters on the microstructure and hardness of the melted zone were deduced from the metallographic analyses and Vickers micro-indentation tests of the cross sections of this composite zone. Such a zone was constituted always with hard titanium carbide and ductile metallic titanium, some times with the presence of lubricating graphite inclusions. The main advantage of such a surface treatment of titanium is to synthesize, under clearly defined irradiation conditions, a self-lubricating composite coating that resists abrasive or adhesive wear.
\end{abstract}

Keywords: Hardness; Titanium; Graphite; Laser; Surface treatment; Surface alloying; Wear

\section{Introduction}

The synthesis of surface alloys by laser irradiation is a high performance process to improve resistance against corrosion [1-5] and to harden the surface of metals [6-11] such as titanium. This treatment is generally achieved by using a continuous wave laser. As for the other surface treatments its objective is to associate the bulk properties of the treated metal with chemical or mechanical new surface properties. It is necessary to control the chemical composition and the microstructure of the surface alloy in order to optimize surface properties.

Titanium and titanium-based alloys are outstanding for their high mechanical strength comparable to that of the best steels, which is associated to their light specific mass $\left(\sim 4.5 \mathrm{~g} \mathrm{~cm}^{-3}\right)$. The synthesis of composite coatings made of hard titanium carbide particles embedded in metallic titanium

\footnotetext{
* Corresponding author. Tel.: +332 401426 27; fax: +33240172618. E-mail address: courant@lamm.univ-nantes.fr (B. Courant).
}

matrix is sought to improve the mechanical surface properties of the metal. Titanium carbide, TiC, is a refractory material which has a melting temperature about $3170{ }^{\circ} \mathrm{C}$ and a high hardness ranging between 2500 and $3000 \mathrm{HV}$. This explains for instance its use to coat cutting tools.

The surface melting by laser irradiation is investigated as a process capable of producing binary titanium-carbon coatings made of metallic titanium reinforced with $\mathrm{TiC}$ ceramic particles. The relationships between the irradiation parameters and the resultant solidification microstructures are therefore studied systematically, because such a surface treatment of titanium is capable of finding various technological applications.

\section{Experiments}

Titanium samples of $20 \mathrm{~mm} \times 20 \mathrm{~mm}$ area and purity above $99 \%$ were cut from foils $3.2 \mathrm{~mm}$ thick. Their surface was then polished up to grade 1000 to obtain the same surface 


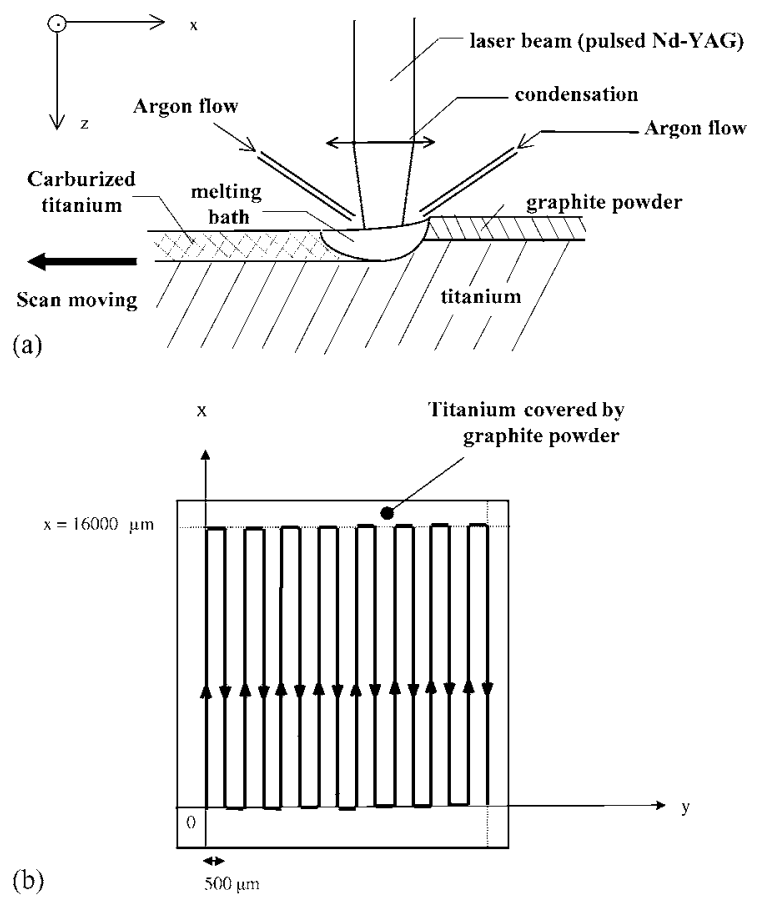

Fig. 1. Schematic representation of the experimental arrangement: (a) crosssection and (b) front view. The samples were moved under the laser beam by means of a numerically driven $X-Y$ table.

state for all the samples. A film of graphite powder having particle diameters around $1 \mu \mathrm{m}$ was then deposited on the polished titanium. The deposited graphite thickness around $20 \mu \mathrm{m}$ was checked by weighting samples. The irradiation treatments were carried out using a pulsed Nd-YAG laser of maximum power $300 \mathrm{~W}$ which emitted energy pulses up to $30 \mathrm{~J}$ with durations ranging from 0.1 to $25 \mathrm{~ms}$. The samples were moved under the laser beam by means of a numerically driven $X-Y$ table. The irradiated area was a square of $16 \mathrm{~mm}$ $\times 16 \mathrm{~mm}$. The oxidation of the samples was prevented by an argon stream directed on to the irradiation zone with $101 / \mathrm{min}$ as flow rate (Fig. 1).

The operative parameters connected with the laser source and the $X-Y$ table motion were as follows [12]:

- pulse energy, $E$;

- pulse duration, $\tau$;

- pulse emission frequency, $f$

- alternative motion speed along axis $X, V$;

- discontinuous displacement along axis $Y$ between each $X$ scan, $\Delta Y$.

The value $500 \mu \mathrm{m}$ was chosen for this last parameter in order to obtain a good compromise between duration and uniformity for all the irradiation treatments with surface melting.

According to a previous study [13] the heat transfer through the irradiated material was considered as dependent on four relevant irradiation parameters. On one hand, two parameters characterized each laser pulse:
- surface density of deposited energy, $F\left(\mathrm{~J} \mathrm{~m}^{-2}\right)$;

- pulse power, $P(\mathrm{~W})$.

On the other hand, two additional parameters described the succession of laser pulses:

- time ratio of laser emission, $B$;

- superposition ratio of two areas successively irradiated, $R$.

These four irradiation parameters were dependent on the operative parameters as follows:

$F=\frac{E}{2 \tau V r+\pi r^{2}}$

$P=\frac{E}{\tau}$

$B=\tau f$

$R=\frac{\overline{b c}}{\overline{a c}}=\frac{2 r+(\tau-(1 / f)) V}{2 r+\tau V}$

The radius, $r$, of the laser beam on the irradiated surface is taken into account in the expressions (1) and (4). Minimum and maximum values of the parameters $B$ and $R$ were first chosen. The laser source used allowed the parameter $B$ to vary from 0 up to 0.6 . The values $B_{1}=0.1$ and $B_{2}=0.5$ were therefore chosen. On the other hand, the high values $R_{1}=0.5$ and $R_{2}=0.9$ were selected for the superposition ratio in order to form homogeneous surface alloys with regular thickness, owing to the wide intersections of the melted zones induced by the successive laser pulses. The ranges of variation for the other parameters, $F$ and $P$, were then fixed taking into account the characteristics of the laser source used (Table 1).

The last parameter considered for this study was the carbon thickness deposited on titanium before irradiation. Graphite powder layers of about ten micrometers thick could be melted owing to the power of the laser beam. The graphite thickness used for our study was always $20 \pm 3 \mu \mathrm{m}$. This thickness was verified by weighing, whereas the pulse energy, $E$, was measured by means of a fluxmeter before each irradiation treatment.

The experiments comprised thirteen irradiation tests in various conditions presented in Table 2. Each sample was investigated by X-ray diffraction spectroscopy (XRD), scanning electron microscopy (SEM), energy dispersion of Xemission (EDX) and Vickers microhardness testing. Microhardness testing was carried out with a load of $200 \mathrm{gf}$ applied for 15 seconds. The micro-indentations were carried out along three lines on the cross sections corresponding to

Table 1

Characteristics of the pulsed Nd-YAG laser used to irradiate titanium

\begin{tabular}{ll}
\hline Pulse energy & $E<35 \mathrm{~J}$ \\
Pulse duration & $0.2 \mathrm{~ms}<\tau<25 \mathrm{~ms}$ \\
Pulse power & $P<7000 \mathrm{~W}$ \\
Pulse emission frequency & $1 \mathrm{~Hz}<f<1000 \mathrm{~Hz}$ \\
Mean power & $P_{\text {mean }}<300 \mathrm{~W}$ \\
\hline
\end{tabular}


Table 2

Relationships between relevant parameters and mass percentages of lost and incorporated carbon, for different irradiation treatments

\begin{tabular}{|c|c|c|c|c|c|c|c|}
\hline \multirow{2}{*}{$\begin{array}{l}\text { Irradiation } \\
\text { treatment }\end{array}$} & \multicolumn{4}{|c|}{ Relevant parameters } & \multicolumn{3}{|l|}{ Balance of carbon } \\
\hline & $R$ & $B$ & $F\left(\mathrm{~J} \mathrm{~mm}^{-2}\right)$ & $P\left(\mathrm{~J} \mathrm{~s}^{-1}\right)$ & $\begin{array}{l}\text { Deposited } \\
\text { graphite thickness, } \\
e_{\mathrm{C}}(\mu \mathrm{m})\end{array}$ & $\begin{array}{l}\text { Mass percentage } \\
\text { of lost carbon, } \\
P_{\mathrm{p}}(\%)\end{array}$ & $\begin{array}{l}\text { Mass percentage } \\
\text { of incorporated } \\
\text { carbon, } P_{\mathrm{i}}(\%)\end{array}$ \\
\hline R1B1F1P2 & $0.5 \pm 0.2$ & $0.100 \pm 0.006$ & $4.4 \pm 0.4$ & $1.11 \times 10^{3} \pm 0.11 \times 10^{3}$ & $18.8 \pm 1.0$ & $77.8 \pm 11.3$ & $24.3 \pm 7.0$ \\
\hline R1B1F2P2 & $0.5 \pm 0.2$ & $0.100 \pm 0.006$ & $5.6 \pm 0.4$ & $1.41 \times 10^{3} \pm 0.14 \times 10^{3}$ & $21.8 \pm 1.0$ & $78.1 \pm 10.3$ & $31.1 \pm 6.7$ \\
\hline R1B1F1P1 & $0.5 \pm 0.2$ & $0.099 \pm 0.002$ & $7.4 \pm 0.5$ & $2.22 \times 10^{2} \pm 0.15 \times 10^{2}$ & $19.6 \pm 1.0$ & $72.6 \pm 10.7$ & $25.8 \pm 6.9$ \\
\hline $\mathrm{R} 1 \mathrm{~B} 1 \mathrm{~F} 2 \mathrm{P} 1$ & $0.5 \pm 0.2$ & $0.099 \pm 0.002$ & $11.8 \pm 0.7$ & $3.56 \times 10^{2} \pm 0.25 \times 10^{2}$ & $21.2 \pm 1.0$ & $78.1 \pm 10.6$ & $27.1 \pm 6.6$ \\
\hline R1B2F1P1 & $0.5 \pm 0.2$ & $0.50 \pm 0.02$ & $2.0 \pm 0.1$ & $2.41 \times 10^{2} \pm 0.19 \times 10^{2}$ & $20.3 \pm 1.0$ & $71.4 \pm 10.3$ & $14.7 \pm 5.8$ \\
\hline $\mathrm{R} 1 \mathrm{~B} 2 \mathrm{~F} 2 \mathrm{P} 1$ & $0.5 \pm 0.2$ & $0.50 \pm 0.01$ & $4.0 \pm 0.4$ & $1.64 \times 10^{2} \pm 0.11 \times 10^{2}$ & $18.6 \pm 1.0$ & $55.2 \pm 9.7$ & $39.1 \pm 8.4$ \\
\hline R2B1F1P2 & $0.89 \pm 0.04$ & $0.100 \pm 0.006$ & $4.6 \pm 0.4$ & $1.11 \times 10^{3} \pm 0.11 \times 10^{3}$ & $19.8 \pm 1.0$ & $48.5 \pm 8.8$ & $62.8 \pm 9.9$ \\
\hline $\mathrm{R} 2 \mathrm{~B} 1 \mathrm{~F} 2 \mathrm{P} 2$ & $0.89 \pm 0.04$ & $0.100 \pm 0.006$ & $5.9 \pm 0.4$ & $1.41 \times 10^{3} \pm 0.14 \times 10^{3}$ & $21.1 \pm 1.1$ & $40.4 \pm 7.8$ & $69.5 \pm 10.2$ \\
\hline R2B1F1P1 & $0.89 \pm 0.04$ & $0.099 \pm 0.002$ & $7.7 \pm 0.5$ & $2.22 \times 10^{2} \pm 0.15 \times 10^{2}$ & $20.9 \pm 1.0$ & $38.5 \pm 7.6$ & $65.0 \pm 9.6$ \\
\hline R2B1F2P1 & $0.89 \pm 0.04$ & $0.099 \pm 0.002$ & $12.4 \pm 0.7$ & $3.56 \times 10^{2} \pm 0.25 \times 10^{2}$ & $20.5 \pm 1.1$ & $36.2 \pm 7.6$ & $65.0 \pm 10.0$ \\
\hline R2B2F1P1 & $0.88 \pm 0.04$ & $0.49 \pm 0.02$ & $2.3 \pm 0.2$ & $2.03 \times 10^{2} \pm 0.16 \times 10^{2}$ & $20.0 \pm 1.0$ & $51.9 \pm 8.5$ & $45.9 \pm 8.0$ \\
\hline $\mathrm{R} 2 \mathrm{~B} 2 \mathrm{~F} 2 \mathrm{P} 1$ & $0.88 \pm 0.04$ & $0.50 \pm 0.01$ & $3.6 \pm 0.2$ & $1.11 \times 10^{2} \pm 0.08 \times 10^{2}$ & $19.6 \pm 0.9$ & $31.4 \pm 7.2$ & $61.5 \pm 9.6$ \\
\hline $\mathrm{R} 2 \mathrm{~B} 2 \mathrm{~F} 2 \mathrm{P} 2$ & $0.88 \pm 0.04$ & $0.50 \pm 0.01$ & $5.4 \pm 0.2$ & $1.64 \times 10^{2} \pm 0.11 \times 10^{2}$ & $21.4 \pm 1.0$ & $35.4 \pm 7.1$ & $70.8 \pm 9.8$ \\
\hline
\end{tabular}

Table 3

Atom percentage of carbon and mean hardness in the melted zone

\begin{tabular}{llcl}
\hline $\begin{array}{l}\text { Irradiation } \\
\text { treatment }\end{array}$ & $\begin{array}{l}\text { Thickness of } \\
\text { melted zone } \\
(\mu \mathrm{m})\end{array}$ & $\begin{array}{l}\text { Atom percentage } \\
\text { of carbon in } \\
\text { melted zone }(\%)\end{array}$ & $\begin{array}{l}\text { Average hardness } \\
\text { in melted zone } \\
(\mathrm{HV})\end{array}$ \\
\hline R1B1F1P2 & $120 \pm 20$ & $7.1 \pm 2.9$ & $338 \pm 5$ \\
R1B1F2P1 & $140 \pm 20$ & $7.6 \pm 2.6$ & $381 \pm 5$ \\
R1B1F2P2 & $145 \pm 5$ & $8.5 \pm 1.8$ & $368 \pm 15$ \\
R1B1F1P1 & $100 \pm 2$ & $9.2 \pm 2.3$ & $388 \pm 16$ \\
R2B1F2P2 & $242 \pm 23$ & $10.8 \pm 1.9$ & $471 \pm 17$ \\
R2B1F2P1 & $212 \pm 13$ & $11.1 \pm 1.8$ & $588 \pm 25$ \\
R2B1F1P2 & $180 \pm 2$ & $12.2 \pm 1.5$ & $444 \pm 16$ \\
R2B1F1P1 & $107 \pm 18$ & $20.1 \pm 4.8$ & $605 \pm 21$ \\
R2B2F2P2 & $40 \pm 20$ & $43.1 \pm 16.8$ & $700 \pm 35$ \\
\hline
\end{tabular}

the beginning, the middle and the end of the irradiation treatment, in order to calculate the average hardness in melted zone. There was no significant difference between the three indentation lines for the same sample. The average hardness, deduced from micro-indentations, in melted zone and its accuracy are given in Table 3 for the different irradiation treatments.

\section{Results and discussion}

The Fig. 2 shows the titanium-carbon phase diagram [14]. The phase $\gamma$ is the titanium carbide phase $\mathrm{TiC}_{1-x}$ where $x$ can vary in a large interval. The $\alpha-\beta$ transformation of pure titanium at $883^{\circ} \mathrm{C}$ is also to be noted. It is important to remind that in case of laser treatments the variations in temperature are very fast and so lead to a non-equilibrium state.

Three zones of different microstructures were revealed on the metallographic cross section of each sample after laser irradiation:

- the melted zone (MZ), as the first surface region, where the temperatures had exceeded the melting temperature of ti- tanium $\left(\sim 1660^{\circ} \mathrm{C}\right)$; the thickness ranged between one and several hundred micrometers, depending on the irradiation conditions, for such a zone;

- the heat affected zone (HAZ), as the underlying region, where the temperatures had exceeded the phase transformation temperature of titanium $\left(\sim 880^{\circ} \mathrm{C}\right)[15]$; its thickness reached some hundred micrometers; the typical acicular microstructure, for such a zone, resulted from the alpha/beta transformation of titanium;

- the non-affected zone (NAZ), where the initial equiaxed microstructure of titanium was preserved.

The MZ thicknesses generated by different irradiation treatments are given in Table 3. For a maximum time ratio $\left(B_{2}=0.5\right) \mathrm{MZ}$ was thin or non-existent. The greater difficulty to melt titanium was due to both the weak pulse power, $P$, and the low deposited energy densities, $F$, which were limited by the mean power of the laser used, according to the inequation $B P<300 \mathrm{~W}$. The part of carbon being assumed to be mixed with titanium was not melted under the extreme circumstances corresponding to the irradiation treatment (R1B2F1P1). In such a case, this carbon part remained in the graphite state and was only fixed on the titanium surface by solidification of the thin layer of molten titanium. For each irradiation treatment (Table 3 ) the atom percentage of carbon mixed with titanium inside the melted zone was deduced from the melted zone thickness and from the previously calculated mass of mixed carbon. Accuracies of these two measurement results allow to calculate a minimum and a maximum value. The samples irradiated with the high superposition ratio $\left(R_{2}=0.9\right)$ generated melted zones having the highest carbon atom percentages. This effect was intensified if the samples were irradiated with the maximum time ratio $\left(B_{2}=0.5\right)$ because of the thinner melted titanium layers which resulted [16]. 


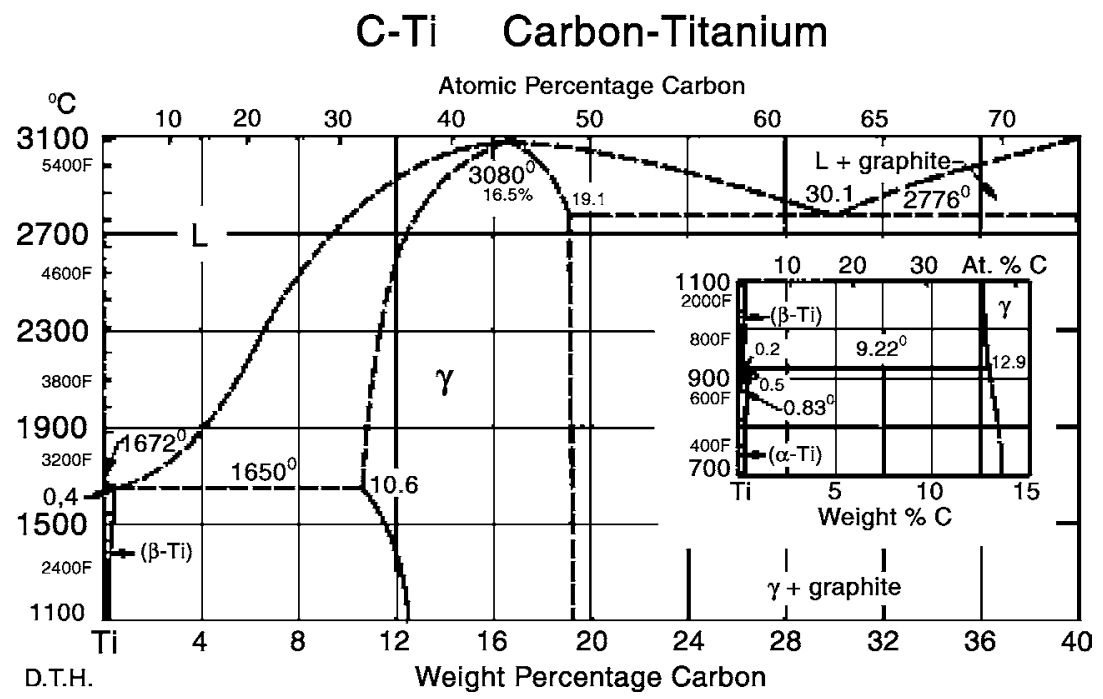

Fig. 2. Titanium-carbon phase diagram.

\subsection{Effects of the superposition ratio}

The mass percentages of carbon lost and mixed respectively during irradiation (Table 2) were deduced from the sample weight before and after its irradiation treatment. The superposition ratio, $R$, had a strong influence on the mixing of carbon with melted titanium. For all the irradiation treatments with the ratio $R_{2}=0.9$, the mean mass percentage 62.9 $\pm 9.6 \%$ of deposited carbon was mixed. The lower ratio $R_{1}$ $=0.5$ induced only the mixing of $27.0 \pm 9.9 \%$ of carbon. The superposition of the successive irradiated areas with $R_{2}$ $=0.9$ resulting from the slower scan speed of the sample induced a more gradual heating of the graphite powder layer. The carbon loss, by projection of carbon particles due to the fast thermal expansion of the gases trapped between the particles of graphite powder, was therefore reduced in this case. The amount of carbon mixed with melted titanium was thus increased. This was confirmed by the weight measurements. In all cases, the mass of residual graphite after irradiation is not measurable. For $R_{2}=0.9$, the mean mass percentage of carbon lost by projection was $40.4 \pm 7.4 \%$, whereas for $R_{1}$ $=0.5$ this percentage was increased to $72.3 \pm 8.8 \%$. So, the stronger superposition ratio produces an enrichment in titanium carbide of the melted zone (MZ), if this zone does not become too thick.

\section{2. $M Z$ microstructures for irradiations with weak superposition ratio $\left(R_{1}=0.5\right)$}

The melted zones generated from the irradiation treatments (R1B1F1P2), (R1B1F2P2), (R1B1F1P1) and (R1B1F2P1) contained low carbon atom percentages (7.1 \pm $2.9 \%$ to $9.2 \pm 2.3 \%$ ). Their metallographic cross sections revealed a metallic matrix with a very fine eutectic microstructure and dendritic titanium carbide grains $\left(\mathrm{TiC}_{1-x}\right)$ whith micrometric sizes. This corresponds to the titanium-carbon phase diagram (Fig. 2).

During the treatments (R1B2F1P1) and (R1B2F2P1), only a very thin titanium layer was melted. The titanium surface after irradiation was covered by an adherent layer of unmelted graphite because its melting temperature $\left(3652^{\circ} \mathrm{C}\right)$ is much higher than that of titanium $\left(1660^{\circ} \mathrm{C}\right)$ [17].

\section{3. $M Z$ microstructures for irradiations with strong superposition ratio $\left(R_{2}=0.9\right)$}

Sometimes the melted zones of the samples irradiated with the stronger superposition ratio exhibited microstructures containing heterogeneities. Such structure defects were present in the cases of the weaker pulse powers (R2B1/2F1/2P1), whereas they were absent for the stronger pulse powers (R2B1F1/2P2). The carbon and titanium distributions in the melted zones were deduced from the SEM observations and EDX micro-analyses carried out on their cross sections previously etched.

Fig. 3 shows the secondary electron micrograph and X-ray image for the melted zone (R2B1F1P1). The heterogeneities are rich in carbon and very poor in titanium. Moreover, the presence of graphite in this same melted zone was detected by X-ray diffraction (Fig. 4). Consequently, such heterogeneities correspond to unmelted graphite inclusions which are embedded in the melted zone.

Numerous graphite inclusions were revealed in the heterogenous melted zones generated by the irradiation treatments (R2B2F1P1), (R2B2F2P2) and (R2B2F2P1). This is explained by the too low temperature reached in the melted pool, insufficient to generate the carbon melting. We have shown for these irradiation treatments that temperature does not exceed $2000-2500{ }^{\circ} \mathrm{C}$ [10] when the atom percentage of carbon mixed with titanium inside the melted zone lies 
(a)

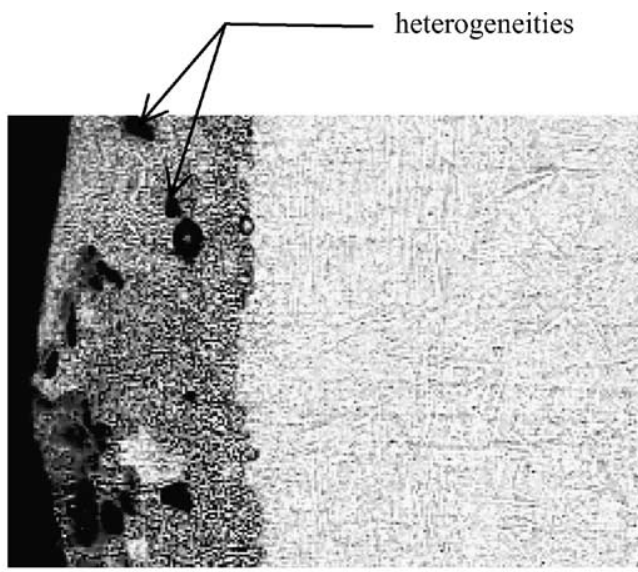

$10 \mu \mathrm{m}$

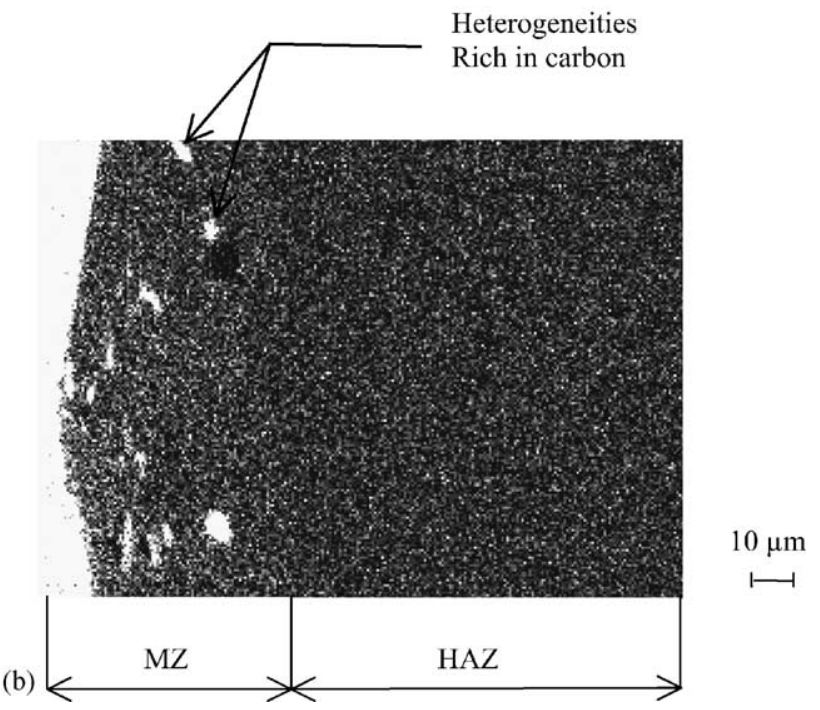

Fig. 3. (a) Heterogeneities in melted zone as revealed by the secondary electron micrograph for the irradiation treatment R2B1F1P1. (b) X-ray-image of the same part of melted zone and heat affected zone for the irradiation treatment R2B1F1P1.The white areas are rich in carbon.

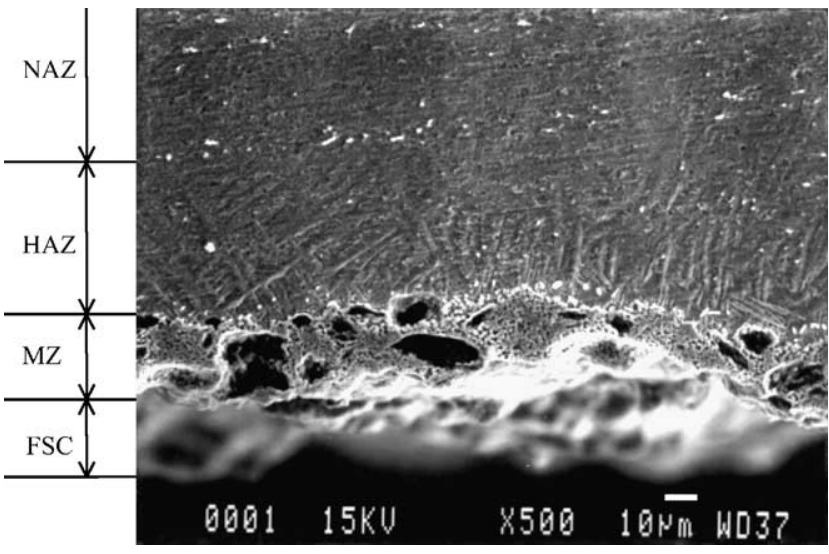

Fig. 5. SEM micrograph of the cross section of a self-lubricating composite coating (FSC: free surface of coating).

between $25 \%$ and $60 \%$. The titanium-carbon phase diagram shows in this case that titanium and carbon are not gathered in an homogeneous liquid phase. However, such structural characteristics for the melted zone can be sought in order to improve its tribological behaviour. A previous paper [18] described the possibility of choosing the laser irradiation parameters in order to produce a self-lubricating composite coating, made of titanium carbide as the hard component, metallic titanium as the ductile component and graphite inclusions acting as the solid lubricant (Fig. 5).

Two kinds of morphology for the titanium carbide phase were revealed after removal of the titanium matrix by chemical etching, either the dendritic grains or the globular grains. The EDX analyses showed that such grains were effectively a combination of carbon and titanium, in agreement with the $\mathrm{X}$-ray diffraction analyses that showed the presence of the titanium carbide phase, $\mathrm{TiC}_{1-x}$.

\section{Intensity (a.u.)}

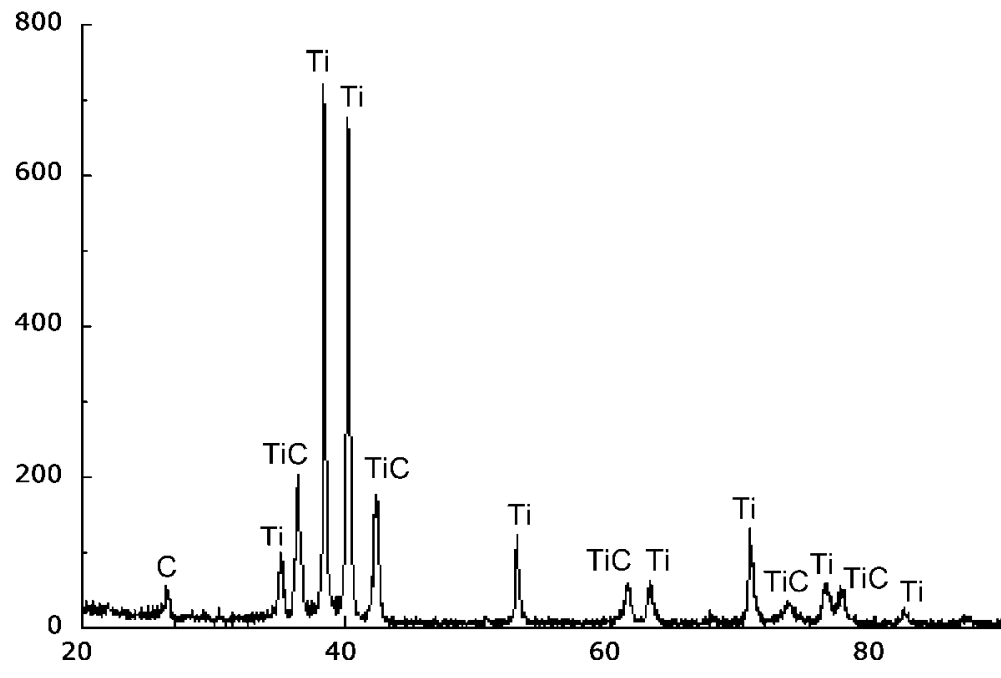

Fig. 4. X-ray diffraction pattern. 


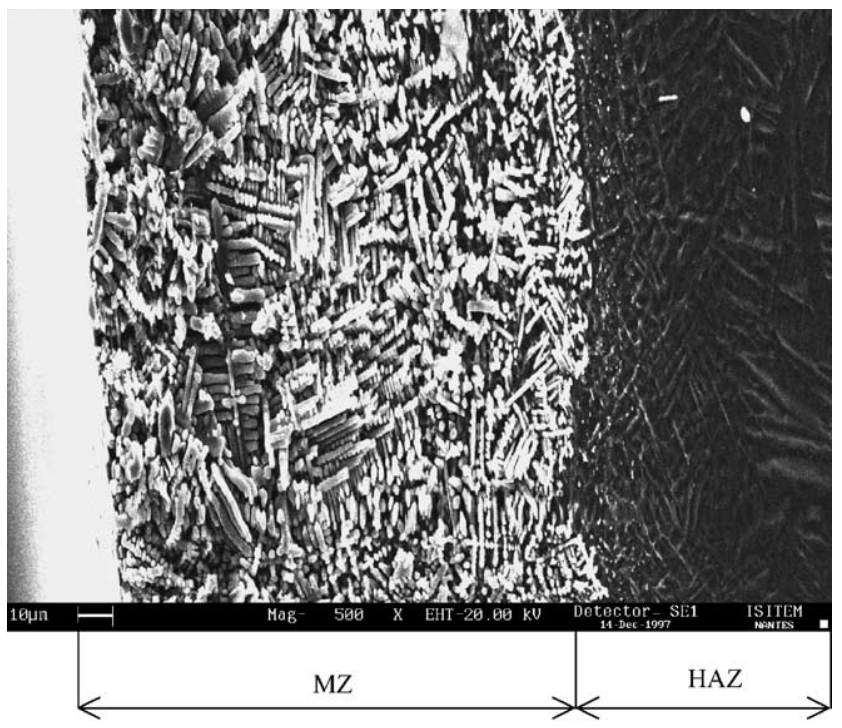

Fig. 6. Cellular dendrites in melted zone corresponding to the irradiation treatment R2B1F1P2.

The removal of titanium by chemical etching revealed cellular dendrites of titanium carbide (Fig. 6) in the melted zones resulting from the irradiation treatments $(\mathrm{R} 2 \mathrm{~B} 1 \mathrm{~F} 1 \mathrm{P} 2)$ and (R2B1F2P2). The lack of preferential direction for the primary arms of the cellular dendrites within the observed melted zones was probably due to the strong convection flows induced by the pulsed irradiation in the melting bath [19-21]. The secondary arms of such dendrites were short, whereas their tertiary arms were non-existent. Their mean lengths were respectively, 20 and $16 \mu \mathrm{m}$. The surface offered much resistance to chemical etching after such irradiation treatments. The EDX spectrum showed that the single-phase surface layer contained titanium and carbon. Very likely, such a surface phase is $\mathrm{TiC}_{1-x}$.

The irradiation treatment (R2B1F2P1) induced simultaneously the dendritic and globular morphologies for the titanium carbide phase.

Melted zones with only titanium carbide of globular morphology (Figs. 7 and 8) were generated by the irradiation treatments (R2B1F1P1), (R2B2F2P1), (R2B2F1P1) and (R2B2F2P2). The carbon contents in the melted zones for these four last treatments ranged between 20 and 60 at. $\%$ and were therefore the highest.

In brief, the kind of solidification microstructure is very dependent on the carbon content mixed with titanium.

For each sample, the Vickers microhardness was measured at different depths on the cross section. The mean hardnesses in the melted zones are given in Table 3. Concerning the irradiation treatments $(\mathrm{R} 2 \mathrm{~B} 2 \mathrm{~F} 2 \mathrm{P} 1),(\mathrm{R} 1 \mathrm{~B} 2 \mathrm{~F} 2 \mathrm{P} 1)$ and (R2B2F1P1), the quantities of unmelted graphite incorporated into the melted zones were too great and prevented the microhardness measurements. The microhardness of the non-irradiated titanium foils was $210 \mathrm{HV}$. A strong relationship was revealed between the carbon content and the mean microhardness in melted zone. The stoichiometric titanium

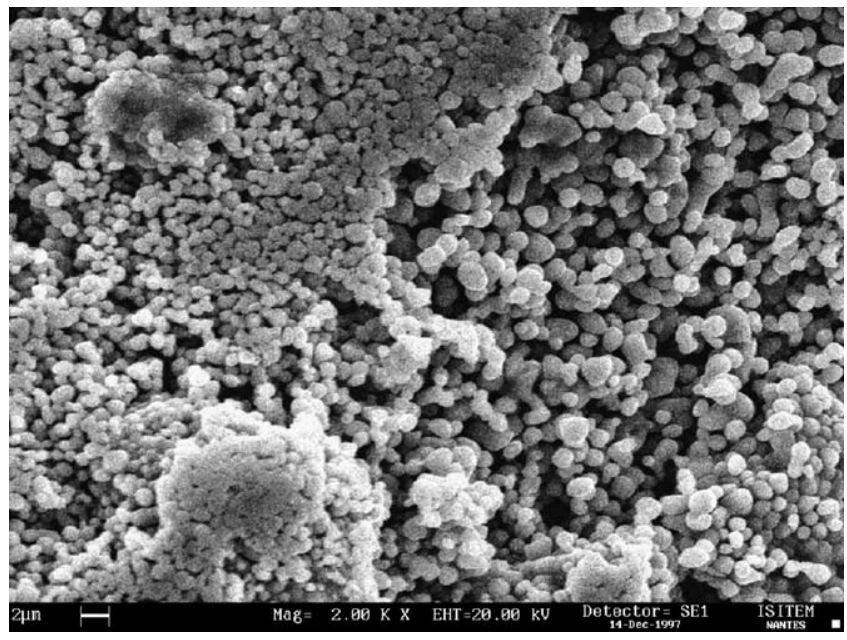

Fig. 7. Melted zone exhibiting a dense globular microstructure corresponding to the irradiation treatment R2B1F1P1.

carbide, TiC, is well known to be an ultra-hard material exhibiting a hardness between 2500 and $3000 \mathrm{HV}$. The hardening induced by the increase of the carbon content in the melted zone was therefore due to the growth, at the expense of the ductile titanium phase, of the hard non-stoichiometric carbide phase, $\mathrm{TiC}_{1-x}$ [22].

Consequently, the surface hardness of the titanium foils is increased easily by surface melting with carburizing under pulsed laser irradiation. The microstructure, corresponding to the globular morphology for the titanium carbide phase and to the higher carbon contents in the melted zone, is more favourable than the dendritic microstructure, because it leads to higher hardnesses around $650 \mathrm{HV}$, and reaching locally 1000 HV. Such a globular microstructure within the melted zone corresponds to a broader occupation of volume by the

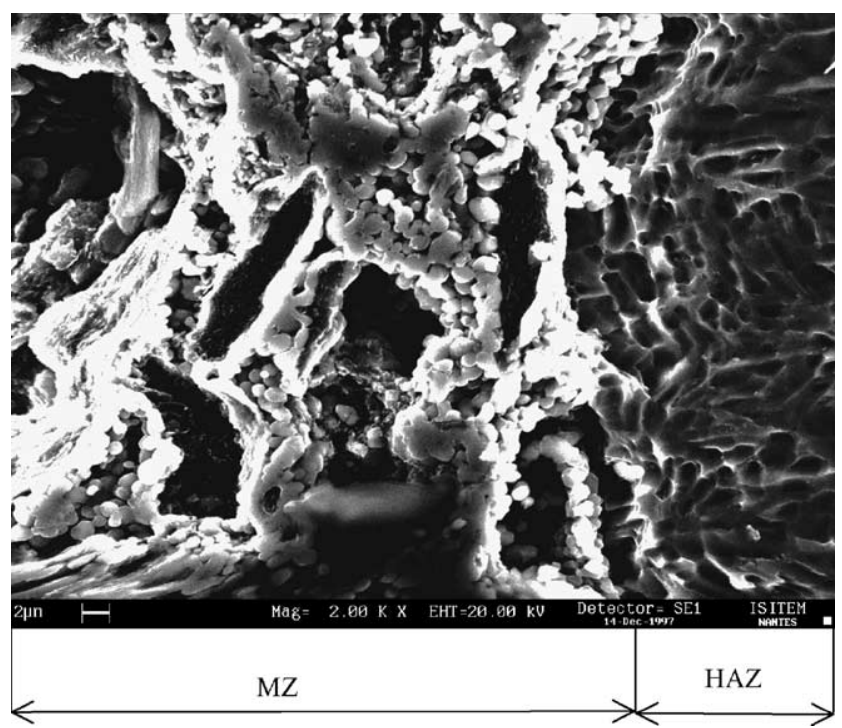

Fig. 8. Melted zone for the irradiation treatment R2B2F2P1, exhibiting a $\mathrm{TiC}_{1-x}$ globular microstructure, with graphite inclusions. 


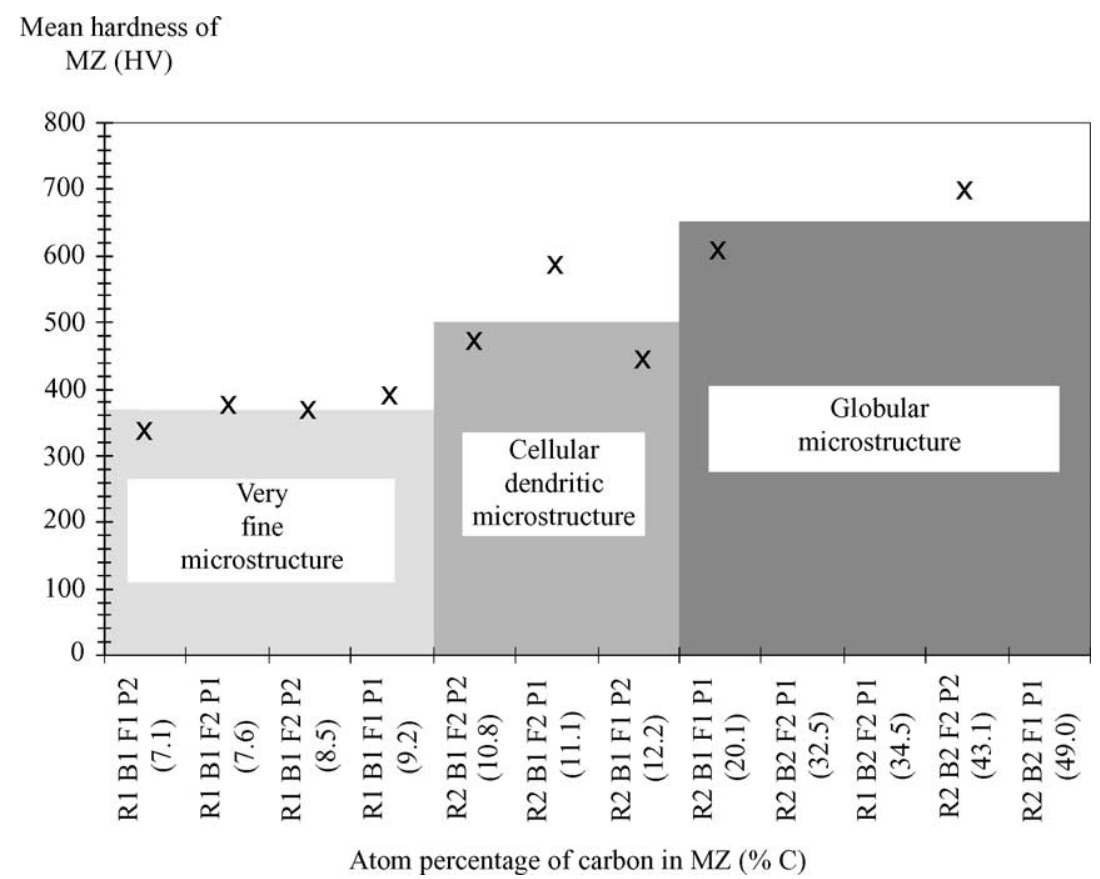

Fig. 9. Diagram of Vickers microhardness versus atomic percentage of carbon indicating the three types of microstructure for the melted zones.

hard phase of titanium carbide and induces a stronger hardening.

\section{Conclusion}

A high ratio $\left(R_{2}=0.9\right)$ induces a stronger incorporation of graphite in the melted zone. The carbon loss by projection of graphite powder particles is significantly reduced during irradiation. A greater mixing of carbon with inclusion of unmelted graphite particles in the melted zone are often associated with a high superposition ratio.

The time ratio, $B$, of the pulsed laser emission has an effect on the melted zone thickness. The low ratio $\left(B_{1}=0.1\right)$ allows an increase in the pulse power, $P$, which leads to the formation of a thicker melted zone rich in carbon and almost free of graphite inclusions. If a good tribological behaviour with low friction and wear resistance is sought, a higher time ratio is required to incorporate still more unmelted graphite.

In practice, the higher the superposition ratio is, or the lower the time ratio is, the longer the irradiation time is necessary for treating the metal surface.

The solidification microstructure of the titanium-carbon mixture within the melted zone is dependent on the relevant irradiation parameters. The titanium surfaces irradiated under the conditions leading to the superposition ratio $R_{1}=0.5$ exhibit melted zones with very fine microstructures made of titanium carbide dendrites $\left(\mathrm{TiC}_{1-x}\right)$ which size is about one micrometer. The melted zones of titanium surfaces irradiated under the highest superposition ratio $R_{2}=0.9$ exhibit microstructures rich either in cellular dendrites or in globular grains of carbide. The solidification microstructure is dependent on the mixed carbon content (atomic percentage) High hardness and high carbon content are related because of the titanium carburizing, according to the diagram (Fig. 9) giving the Vickers microhardnesses and the solidification microstructures for the melted zones obtained under various circumstances. Moreover, the presence in such melted zones of numerous graphite inclusions, acting as a solid lubricant and decreasing friction and abrasive or adhesive wear, improves clearly the tribological behaviour of titanium, in agreement with a previous study.

\section{Acknowledgement}

The authors are grateful to Dr. V. Haÿs (ISITEM, Nantes, France) for the SEM observations and EDX analyses.

\section{References}

[1] M.A. Anjos, R. Vilar, R. Li, M.G. Ferreira, W.M. Steen, K. Watkins, $\mathrm{Fe}-\mathrm{Cr}-\mathrm{Ni}-\mathrm{Mo}-\mathrm{C}$ alloys produced by laser surface alloying, Surf. Coat. Technol. 70 (2/3) (1995) 235-242.

[2] M. Wang, W. Wu, Microstructure of laser-surface-alloyed cast iron with Cr-Al-Y alloy, Surf. Coat. Technol. 72 (3) (1995) 181-188.

[3] P.A. Carvalho, R. Vilar, Laser alloying of zinc with aluminum: solidification structures, Surf. Coat. Technol. 91 (3) (1997) 158-166.

[4] P.H. Chong, Z. Liu, P. Skeldon, G.E. Thompson, Large area laser surface treatment of aluminium alloys for pitting corrosion protection, Appl. Surf. Sci. 208/209 (2003) 399-404.

[5] A. Conde, R. Colaço, R. Vilar, J. de Damborenea, Corrosion behaviour of steels after laser surface melting, Mater. Design 21 (5) (2000) 441-445. 
[6] S. Ettaqi, S. Benayoun, J.J. Hantzpergue, et al., Structural study of a titanium/titanium boride cermet coating formed upon laser fusion of boron on a titanium foil, J. Mater. Chem. 5 (11) (19951905).

[7] S. Ettaqi, V. Hays, J.J. Hantzpergue, G. Saindrenan, J.C. Remy, Mechanical, structural and tribological properties of titanium nitrided by a pulsed laser, Surf. Coat. Technol. 100/101 (1-3) (1998) 428-432.

[8] P. Wu, C.Z. Zhou, X.N. Tang, Laser alloying of a gradient metalceramic layer to enhance wear properties, Surf. Coat. Technol. 73 (1/2) (1995) 111-114.

[9] A.E. Leithy, J. Barralis, G. Contreau, TIG (GTAW) and laser melting of grey and ductile irons, Applications of the surface hardening of cast iron automotive camshafts (Traitements superficiels des fontes grises par refusion TIG et refusion laser), Mem. Etud. Sci. Rev. Metall. (July-August 1992) 89 (7/8) 409-422 (in French), Int. J. Fatigue, vol. 15 (6) November 1993, p. 534.

[10] D.I. Pantelis, E. Bouyiouri, N. Kouloumbi, P. Vassiliou, A. Koutsomichalis, Wear and corrosion resistance of laser surface hardened structural steel, Surf. Coat. Technol. 161 (2-3) (2002) 125-134.

[11] J.-H. Hwang, Y.-S. Lee, D.-Y. Kim, J.-G. Youn, Laser surface hardening of gray cast iron used for piston ring, J. Mater. Eng. Perform. 11 (3) (2002) 294-300.

[12] B. Courant, Fusion et carburation superficielles du titane par irradiation laser multi-impulsionnelle, modélisation thermique, expérimentation et simulation. Thesis ENSAM, no. d'ordre 98.36, France, 1998, $226 \mathrm{p}$.

[13] B. Courant, S. Ettaqi, L. Fouilland-Paillé, S. Benayoun, J.J. Hantzpergue, Thermal simulation of the laser melting process used for elaboration of hard cermet coatings on titanium, Proceedings of the 11th International Conference on the Surface Modification Technologies, Paris, SMT 11, 1997.

[14] Metals Handbook, vol. 8, 8th edition, American Society for Metals.

[15] Smithells Metal Reference Book, 6th edition, Eric A. Brandes, 1983.

[16] B. Courant, J.J. Hantzpergue, S. Benayoun, J.P. L'Huillier, Melting and solidification processes in a moving graphite-covered titanium surface subjected to multi-pulsed laser irradiation, J. Phys. D: Appl. Phys. 34 (2001) 1437-1446.

[17] Handbook of Chemistry and Physics, 63rd edition, CRC Press, Florida, 1982-1983.

[18] B. Courant, J.J. Hantzpergue, S. Benayoun, Surface Treatment of titanium by laser irradiation to improve resistance to dry-sliding friction, Wear 236 (1999) 39-46.

[19] L. Covelli, F. Pierdominici, I. Smurov, S. Tosto, Surface microstructure of titanium irradiated by Nd:YAG pulsed laser in presence of carbon and nitrogen, Surf. Coat. Technol. 78 (1-3) (1996) 196-204.

[20] L.X. Yang, X.F. Peng, B.X. Wang, Numerical modeling and experimental investigation on the characteristics of molten pool during laser processing, Int. J. Heat Mass Transfer 44 (23) (2001) 4465-4473.

[21] J.P. Longtin, K. Hi jikata, K. Ogawa, Laser-induced surface-tensiondriven flows in liquids, Int. J. Heat Mass Transfer 42 (1) (1998) $85-93$.

[22] L. Fouilland-Paille, S. Ettaqi, S. Benayoun, J.J. Hantzpergue, Structural and mechanical characterization of $\mathrm{Ti} / \mathrm{TiC}$ cermet coatings synthesized by laser melting, Surf. Coat. Technol. 88 (1-3) (1997) 204-211. 